\title{
A Conceptual Semi-Humanoid Wireless Robotic Lecturer for Distance Learning (DL)
}

\author{
Victor O. Matthews \\ Department of Electrical \& \\ Information Engineering, \\ Covenant University, \\ Ota, Nigeria
}

\author{
Emmanuel Adetiba \\ Department of Electrical \& \\ Information Engineering, \\ Covenant University, \\ Ota, Nigeria
}

\author{
Felix O. Olowononi \\ Department of Electrical \& \\ Information Engineering, \\ Covenant University, \\ Ota, Nigeria \\ Oluyinka Oni \\ Department of Electrical \& \\ Information Engineering, \\ Covenant University, \\ Ota, Nigeria
}

\begin{abstract}
Information and Communications Technology is causing a worldwide revolution in virtually all fields of human endeavor. The education sector is not left out as the delivery of course content is no longer limited to the traditional teacher-student classroom interaction but also via electronic media. This paper presents a novel approach to e-Learning by leveraging on advancements in Machine-to-Machine communications (M2M), Internet-of-Things (IoT) and robotics technologies to design and construct a semihumanoid class teaching robot that aids teachers, lecturers and other educational personnel in communicating effectively with the students irrespective of their location and the distance using a plastic mannequin. The implementation of the system is achieved through hardware (mannequin) and software designs.
\end{abstract}

The authors successfully developed a plastic mannequin with embedded electronics systems to work as a telepresence lecturer, allowing the elimination of time and distance between a professional remote educator and the students. The device was tested and compared with existing remote teaching technologies such as teleconferencing, telepresence with tablet screens and found to be more reliable, cheaper, and easy to use than the existing ones. The paper therefore concludes that the semi-humanoid robotic lecturer is a disruptive innovation in the world of Distance Education Learning (DEL).

\section{General Terms}

Distance Learning, Robotics,

\section{Keywords}

E-learning, Semi-Humanoid, Robotics, Teleconferencing, Telepresence, Mannequin..

\section{INTRODUCTION}

Concerns about existing or imminent shortfalls in the number of teachers have arisen for several decades in both more and less developed countries [1]. In 2013, United Nations Educational and Scientific and Cultural Organization (UNESCO) estimated that by the year 2015, about 1.6 million more teachers would be needed globally to achieve the goal of Universal Primary Education [2]. However, the challenges faced in education are not only due to lack of access but also the poor quality of education available to those who are privileged to have access. The corresponding relation between the quality of an education system and the quality of teachers brings to the fore the need for the government of nations to intensify their efforts to produce more qualified teachers in order to enhance the quality of learning. There is however an associated cost to this as countries that require additional teachers need to increase their overall budget for teacher's salaries. Sub-Saharan Africa has the greatest need for extra teachers and Nigeria alone accounts for two-fifth of the gap. For example, reports have shown that $\$ 4$ billion is needed annually in Sub-Saharan Africa to pay the additional salaries of the additional primary school teachers required by 2020[3].

The major disruptive influence in education today is technology, for we live in an era where the wealth of data and the exponential growth in the development of new knowledge is challenging institutions to rethink laterally in teaching and learning [4]. As more people adopt new technologies for learning, they will thrive in the emerging world of the Internet of Everything ( $\mathrm{IoE}$ ); the networked connection of people, process, data, and things which is becoming the basis for the Internet of Learning Things [5].

The Internet of Everything is the next step in the evolution of smart objects interconnected things in which the line between the physical object and digital information about that object is blurred [6]. The 2013 Horizon Report predicts that smart objects will become ubiquitous in higher education by 2017, where products like super mechanical's twine [7], a small box described as "the simplest way to connect stuff to the Internet" allows users to link almost any physical object to a local area network. Twine integrates sensors with a cloudbased service, allowing for easy setup.

$\mathrm{IoE}$ in education is in the early stages, but some institutions are leading the way in showing how $\mathrm{IoE}$ can be used effectively in educating persons all over the world. The advent of massive open online courses (MOOCs) is another step toward global education. MOOCs are aimed at large-scale interactive participation and open access via the web. Some of the world's leading universities are making their top professors available free of charge, and online forums that are linked to MOOCs will become spaces for new networks to develop and grow, connecting people from all walks of life 
and giving education to those who do not have access to highquality content or instructors in their own locale [8].

This paper focuses on the impact of Information and Communications Technology in the education sector, and the use of internet of everything (IoET) as a means of advancing e-learning in the academic environments. Recently, information technology has been viewed as a solution to universities' cost and quality problems. Information technology in teaching and learning has created a need to transform how university students learn by using more modern, efficient, and effective alternative tools such as electronic learning (e-learning). With different definitions by different researchers, e-learning however centers on its being a learning method and a technique for the presentation of academic curricula via the internet or any other electronic media inclusive of multimedia, compact discs, satellites, or other new education technologies [9]. A major cause of the popularity of e-learning is that it challenges the traditional "bucket theory" or the "banking concept" of education which assumes that the instructor owns the knowledge and deposits it into the passive students who attend the class [10].

Developments in e-learning and technologies are creating the groundwork for a revolution in education, allowing learning to be individualized (adaptive learning), enhancing learners' interactions with each other (collaborative learning), and transforming the role of the teacher (from disseminator to facilitator) [11].

The design of different types of learning environments can depend on the learning objective, target audience, access and type of content. Presently, the major model of e-learning involves Teleconferencing and Tele-Presence; a major means of communication in real-time which operates by passing across information through some certain kind of display screens using the internet as the medium of communication. Tele-Presence is a new type of interactive education that helps to meet the needs of the $21^{\text {st }}$ century learners by expanding curriculum options, maximizing scarce resources, increasing teacher and student engagement and improve learning outcomes. The top three benefits of Tele-Presence are maximizing budget, increasing access and equity as well as expanding learning [12].

The need to perform a variety of functions independently has made general-purpose autonomous robots popular in recent times. They typically can navigate independently in known spaces, handle their own re-charging needs, interface with electronic doors and elevators and perform other basic tasks. To further increase their functionality and meet the demands of the $21^{\text {st }}$ century, general purpose robots have been developed like computers to link up with networks, software and accessories. They may recognize people or objects, talk, provide companionship, monitor environmental quality, respond to alarms, pick up supplies and perform other useful tasks $[13,14]$. Some of such robots try to mimic human beings and may even resemble people in appearance; this type of robot is called a humanoid robot (Figure 1).

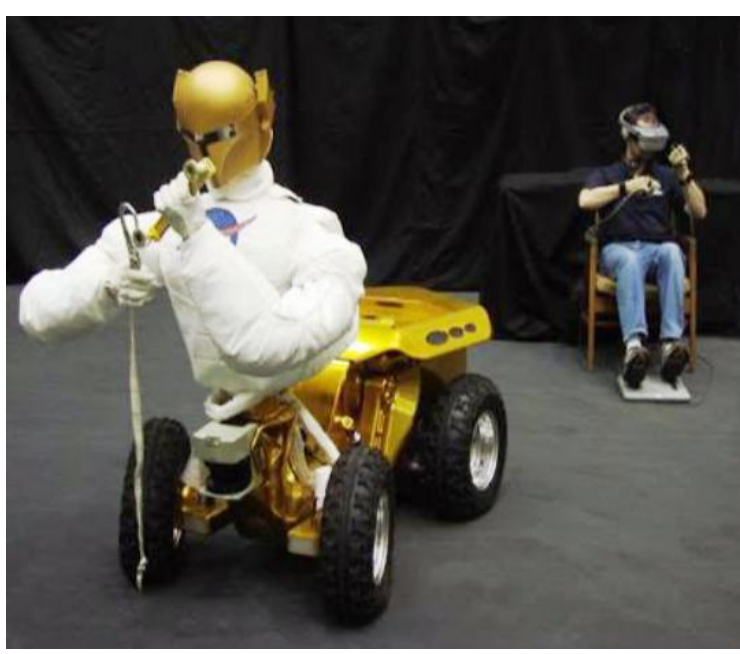

Figure 1: Semi Humanoid Robot (www.robonut.jsc.nasa.gov)

Semi-humanoid robots however are robots that have the look and feel of a human being or perform intelligent function of a human being with the support of a human. Semi-humanoid robots are made up of mechanical body parts, intelligent systems (artificial intelligence), sensors, human-computer interactions techniques. The use of semi-humanoid robots in various fields of human endeavor has been presented by various researchers in [15] - [17].

As the world continues to navigate to a machine to machine $(\mathrm{M} 2 \mathrm{M})$ prospect of doing virtually everything, the academic world cannot be left behind. This project reported herein therefore integrates dynamism and a more recent communication technology; Internet of Things (IoT) in the use of Telepresence devices.

The system comprises of three subsystems namely the robotic sub-system (hardware/embedded systems), the Web-server sub-system (software) and the Control/Users end sub-system (interactive software). The system is operated by remotely controlling the humanoid robot to simulate the human nature as a function of the hardware and software incorporated into it, while the network system utilizes the internet to stream live video feeds from a classroom to the lecturer end and the lecturer's viewing node (computer) is also mirrored back to the class for presentation The Interactive Software will also enable automatic Wi-Fi link to the system in the classroom in order to assess the lecture been delivered as well as have access to previous lectures.

\section{MATERIALS AND METHOD}

This project consists of three parts which are specified either as a hardware or software. These include the robot sub-system (plastic mannequin), the Web-server sub-system (software) and the Control/Users end sub-system (software). The network diagram of the system is as shown in Figure 2 below. 


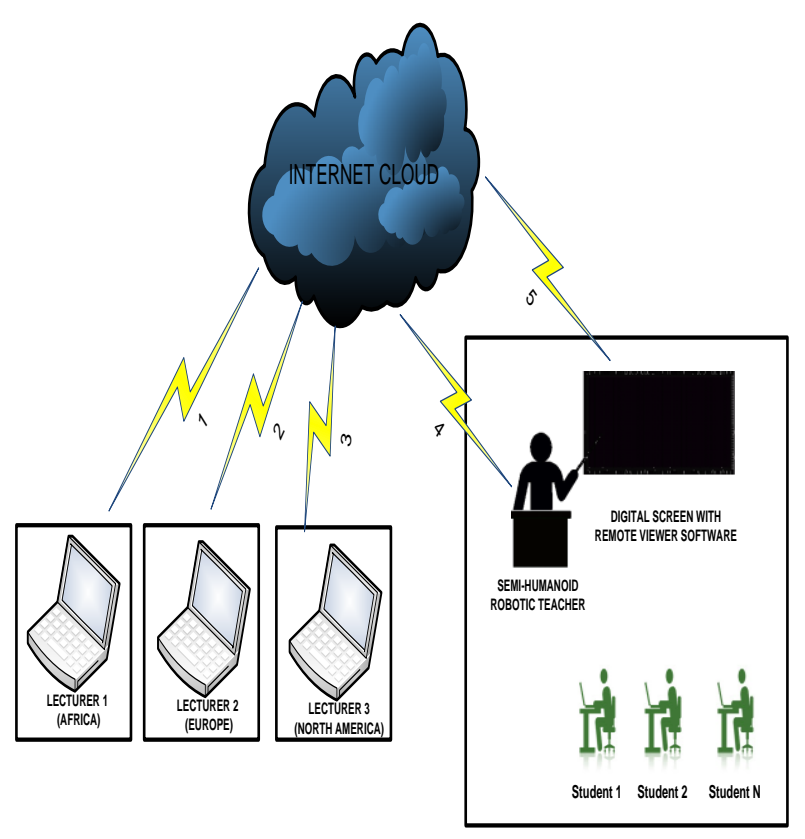

CLASSROOM

\section{Figure 2: Network architecture of the Semi-humanoid} wireless robotic lecturer

A lecturer based in South Africa having been assigned to deliver a lecture according to the time-table $(10-12 \mathrm{am})$ to an audience in Lagos, Nigeria simply logs into the Semihumanoid system with a peculiar identity and password assigned to him. Signallwhich emanates from the remote lecturer is routed through the internet cloud and enables the lecturer to control and manipulate the robot to the assigned lecture hall (through Signal 4) as well as connect with the digital screen (through Signal 5) in the lecture room via a remote viewer software and comfortably deliver the assigned lecture in any format (power point, words etc.) to the remote audience.

The next lecture can also be delivered by other lecturers located in Europe and North America at different times through Signal 2 and Signal 3 respectively.

The robot/hardware subsystem is further divided into three (3) hardware components' sections namely, the head (controller) section, the chest section, the wheel section.

The software design as already stated is divided into two (2) software modules namely the web-server module and the control module. Both the robot subsystem and software design are further discussed in the section below.

\subsection{Robot Sub-System / Hardware Design}

The design of the hardware part of the system is presented in this section. The choice of components, the justification for such choice and the operational flow process are also presented herein. The major devices and components used to accomplish the hardware design of the semi-humanoid robotic teacher include a Raspberry Pi Controller, PTZ Camera Module, Proximity Sensors, Stepper Motor, DC Motor, Microphone, Audio Speaker, Batteries (4.8vdc and $12 \mathrm{vdc}$ ), Battery Chargers (4.8vdc and 12vdc), Stepper Motor Driver, DC Motor Driver, HDMI Cable, Audio to USB Adapter, Wireless Access Point and a Wireless Adapter.
The diagram below shows the general design of the hardware subsystem of this project.

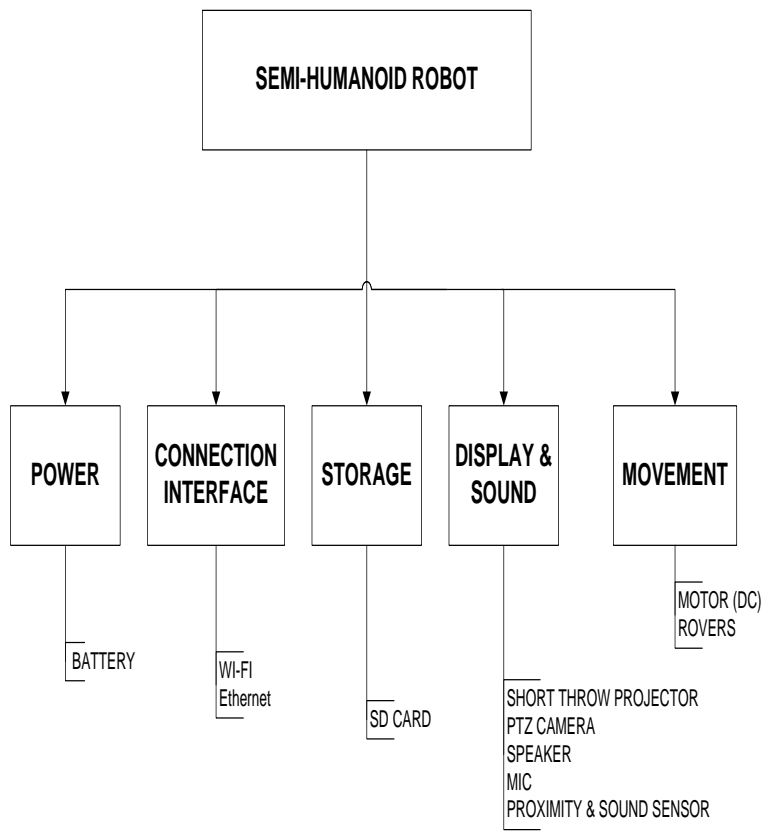

Figure 3. General hardware system design

Furthermore, the hardware is sub-divided into sections which are comparable to parts of the human body. Each section of the hardware design contains a number of components that control its action and helps it to carry out the required functionality. The major sections in the hardware include the head (controller), the chest and the wheel.

\subsubsection{The Head (controller) section}

The design of the head section is responsible for the rotation of the head of the robot so that it can cover the class and allow the lecturer the opportunity of viewing clearly the composition of the class from his remote location (180 degree PTZ viewing). The head section of the system is composed of five major components namely the raspberry pi controller, the stepper motor mechanism, the PTZ camera module, the motion sensor and the microphone.

The raspberry pi controller is the brain of the whole system. It is a low-cost credit-card sized computer with 4 USB ports and 40 GPIO (General Pins for Input and Output) pins for interfacing with other components in the robot system. Raspberry pi GPIO (General Input Output Pins) pins are physical interface between the Pi and external devices. They can act as switches which can turn on or off either the pi or control other devices. It is strategically positioned in the head of the robot system just as the brain resides in the head of the human.

Also residing in the head section of the semi-humanoid robot is a stepper motor which is responsible for moving the head right or left in a number of counts. The stepper motor is one kind of electric motor commonly used in the robotics industry. It is an electromechanical device which operates by converting electrical pulses into discrete mechanical movements. The shaft or spindle of a stepper motor rotates in discrete step increments when electrical command pulses are applied to it in the proper sequence. 
The PTZ camera module is the vision of the robot which is held precisely in the eye hole of the robot body. The two motion sensors (Infra-red proximity sensor) are also positioned on the neck of the robot in the head section to detect motion of anybody coming towards the robot. These sensors are placed on the neck region because of the height of the robot to easily detect bodies (mostly human) at almost any height and distance from the robot. The microphone is also positioned on the neck of the robot in the head section to pick up acoustic signals from the environment when needed for processing. The microphone is positioned in front of the neck in the head section to directly face the audience for the sound input when controlled to accept it. The audio microphone used here is a special one that allows very sensitive vibrations from the environment to be picked up, thereby enabling very good acoustic quality.

\subsubsection{The Chest section}

The chest section is the wiring connection hub of the robot system. The major components that make up the chest section of the system body include the speaker, $4.8 \mathrm{~V}$ direct current battery, the stepper motor driver, direct current motor driver, USB hub and other connecting wires for power and data.

The speaker is strategically positioned in the chest of the robot body. The location where it is places is perforated with holes large enough to pass across the audio signal. The 4.8VDC power source (battery) is used for powering any 5VDC device (raspberry pi) with $5 \%$ power tolerance. The $4.8 \mathrm{VDC}$ battery which is packed to deliver $1600 \mathrm{~mA}(1.6 \mathrm{~A})$ of current at that voltage level has an energy capacity of about four hours of constant use after which it can be recharged. The stepper motor driver, the DC motor driver are also located here, they are positioned in the chest section for ease of carriage and protection. The USB hub is used to power all USB connecting devices or components such as the speaker and the raspberry pi controller. The connecting wires connect the components together from the controller in the head section to the chest section and terminate at the wheel section.

\subsubsection{The Wheel section}

The wheel section is the moving mechanism subsystem of the robot. The supporting platform is the base where the robot body is mounted on for carriage. This carriage system (platform) is supported with some extra weight at the base to conveniently lift the weight of the robot system. This platform or carriage system is wheeled on four (4) tires with which two (2) of the tires are driven directly by DC motors as controlled by the controller of the system. This platform motor mechanism is driven by a $12 \mathrm{VDC}$ battery source place above it.

\subsection{The Software Design}

In this section, the design of the Interactive Software built to enable the functionality of users having connections to web links and mobile devices thereby enabling distance learning is presented herein. Although the physical/hardware design is what is seen as the major part of the robot, in actual fact, the bulk of the work resides in soft design i.e. software. This software design as part of the system design interfaces with the hardware for control and remote access through a network which could be a Local Area Network or the Internet. The web-server and control/user interface design processes (program flow or flow chart) have also been specified in the design form.
The software design of the system is further segmented into two subsystems. These include the web-server subsystem and the control/user end subsystem. The flowcharts illustrating the process of operation of either of these subsystems are presented and discussed in the sections below.

A diagram showing the general design of the software is also presented in Figure 4 below.

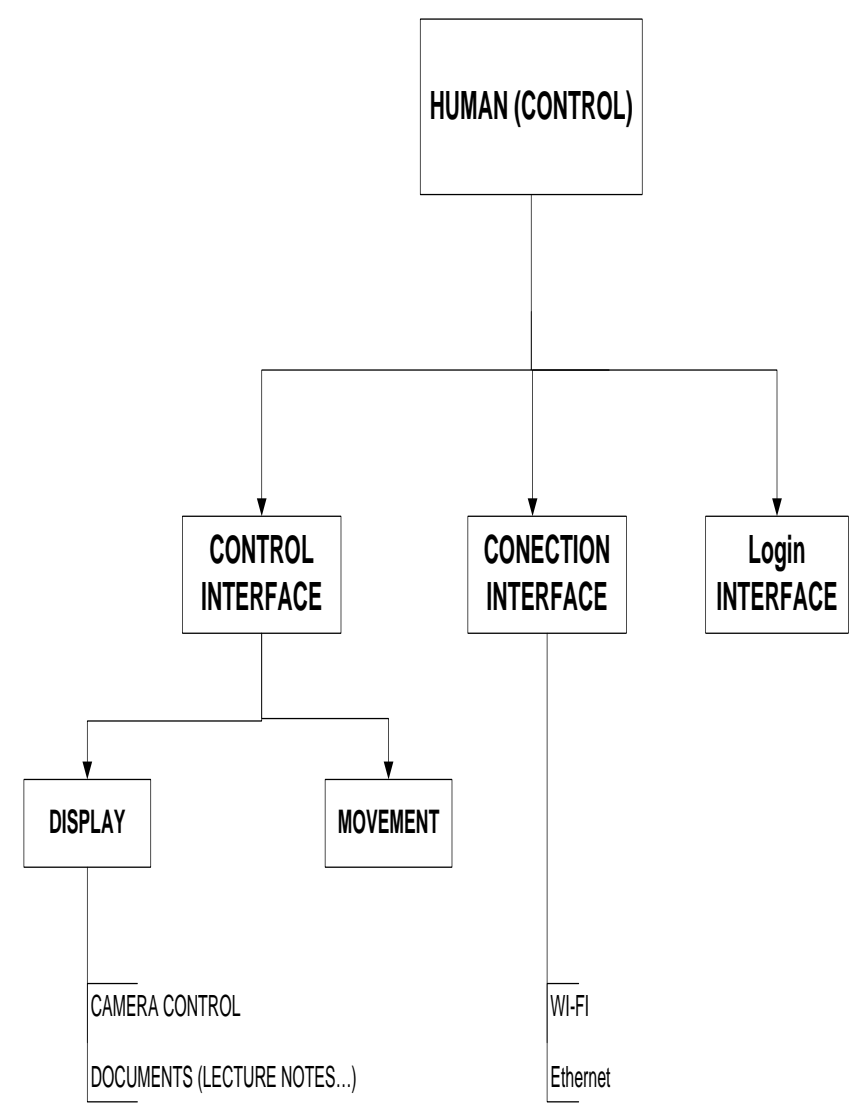

Figure 4. Figure showing general software design methodology

\subsubsection{The Web-Server Sub-System}

The Web-server is a program that uses the client/server model and the World Wide Web's Hypertext Transfer Protocol (HTTP) to serve files that form web pages to web users/clients. The Web-server serves as the middle technology between the client/user and the semi-humanoid robot. In this system, the web-server hosts the control of the robot. The client's computer system utilizes the HTTP to forward its requests to the web server for execution. The Apache webserver runs on a dedicated computer and also on the raspberry pi. The program flow for the web-server is as shown in the figure below. 


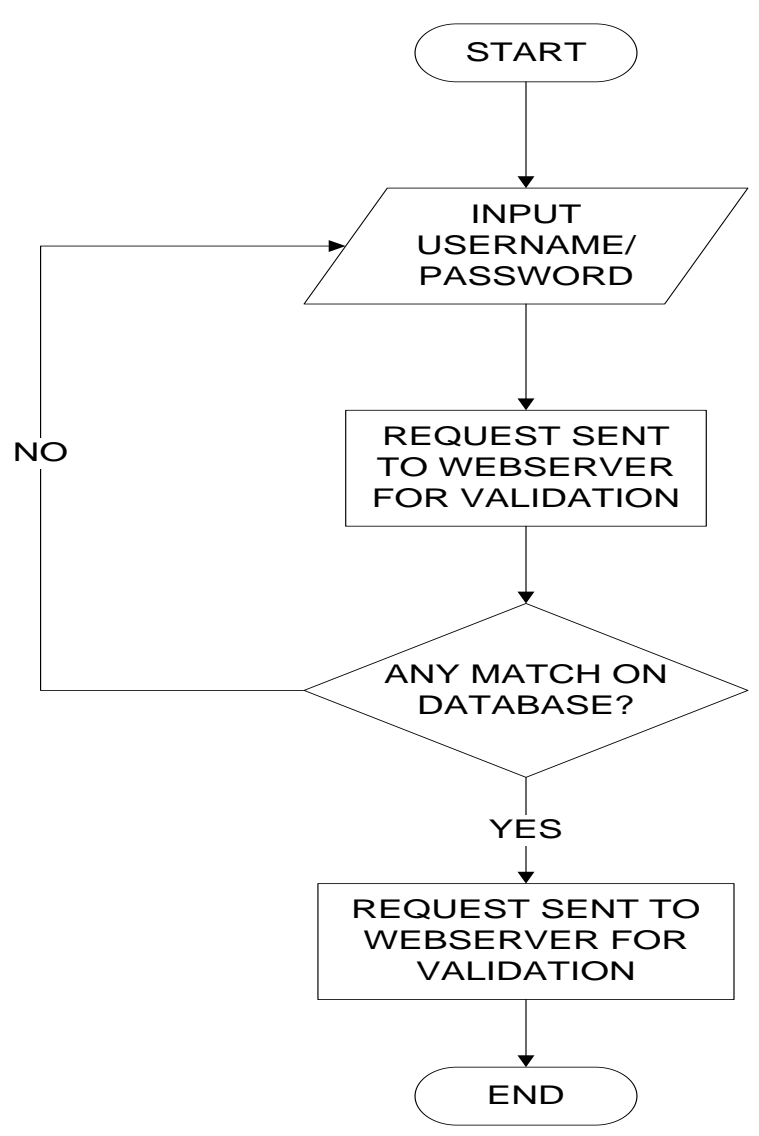

Figure 5. Web-server/Log-in page flow chart

\subsubsection{The Control/User End Sub-System}

The control buttons are designed with HTML image map tags. Each image tag has an 'ID' associated with it; which specifies the JavaScript function that handles the mouse up/mouse down events for that image. When a user clicks on a button, the corresponding JavaScript function will execute in their browser. This function is sent to the web-server which reformats the information and sends it to the python web socket service listening on the robot. A CGI script running on the robot's server is invoked and it sets GPIO pins to perform a function. When the user lets go of the mouse button, the browser detects the mouse up event and calls a JavaScript function which sends the update information to the python web socket listening on the raspberry pi. This in turn calls a clear.cgi function. The 'clear.cgi' function invokes a script on the server that terminates the GPIO pins process. The operational process discussed above is presented in the flowchart below for ease of understanding.

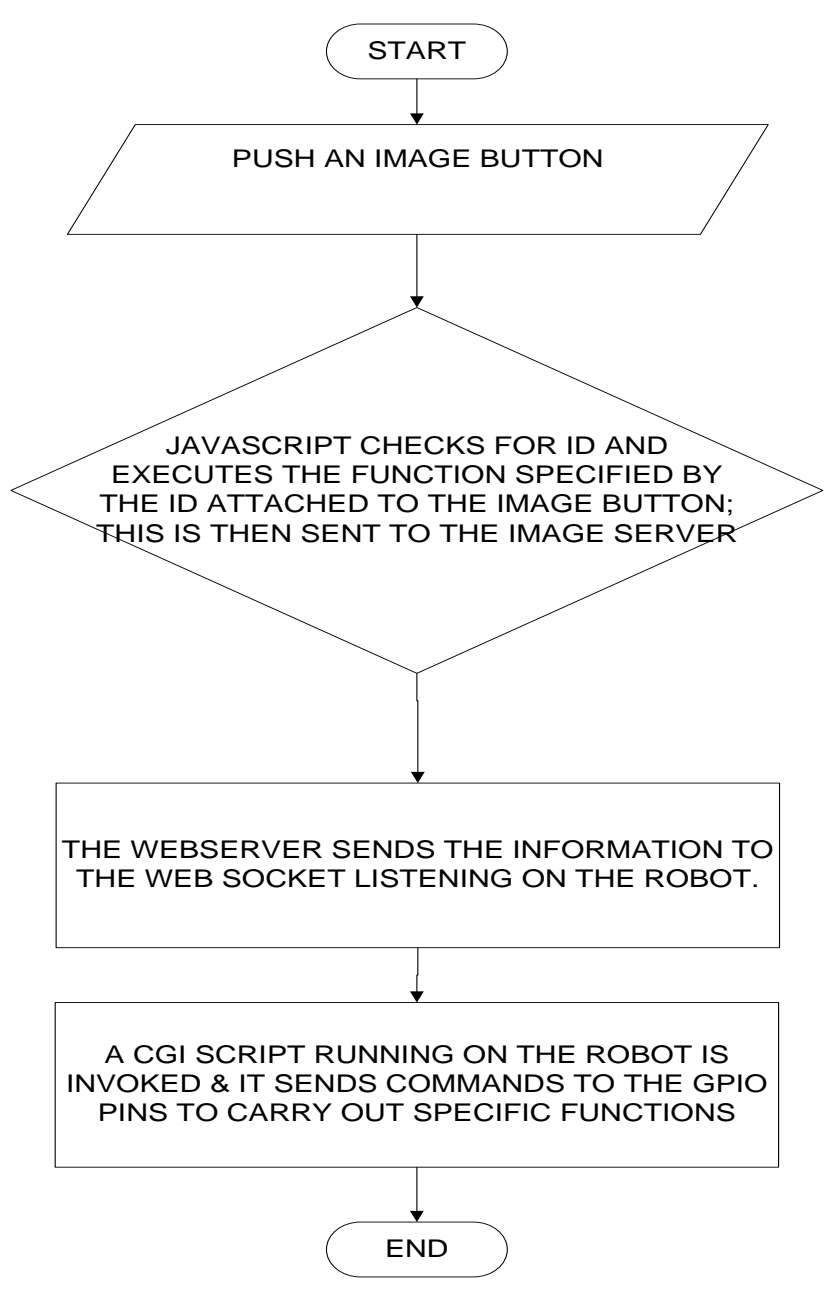

Figure 6. Control/End user flow chart

\section{SYSTEM IMPLEMENTATION}

In the implementation process, the step by step connection methods and approaches are highlighted. The various components used in the robot system as already been explained are interfaced with other components to achieve the designed robot system. To have an easier comprehension of the implementation process, diagrammatic and pictorial views of the interfacing and interconnections are also presented in this section.

This process began with the segmentation of the robot body (mannequin) into head, chest and wheel sections, followed by a precise dimensioning of the body. The head was pierced into two halves and the back of the robot was mark for cutting. The back of the robot was cut with a mechanized saw and the hollow body was open for placement of components such as the network antenna, signal control unit, mini computer and speakers. Figure 7 below illustrates the installation of these components in the chest section. 


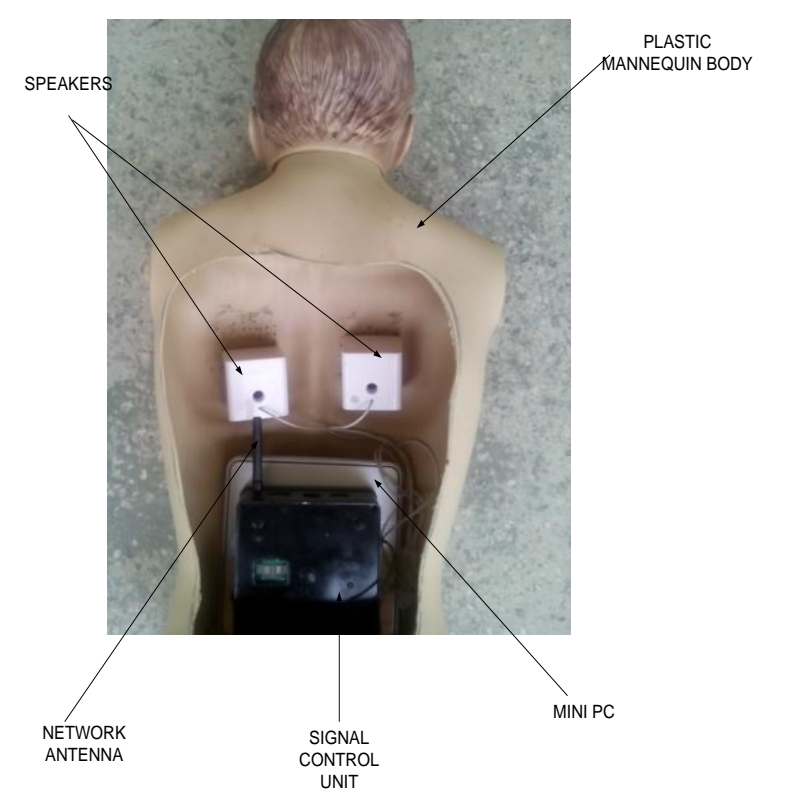

Figure 7. Installation of components in the Chest section

The next stage was the design and construction of the wheel mechanism. A steel platform was dimensioned and drilled for fixing of four (4) rigid rubber tires with support systems. Two (2) of this tyres are directly attached with a DC motor welded in the frontal area of the platform and the other two tires are screwed in the back area of the same platform. A weight of about $10 \mathrm{~kg}$ was welded underneath the platform to give stability to the system when loaded with the components.

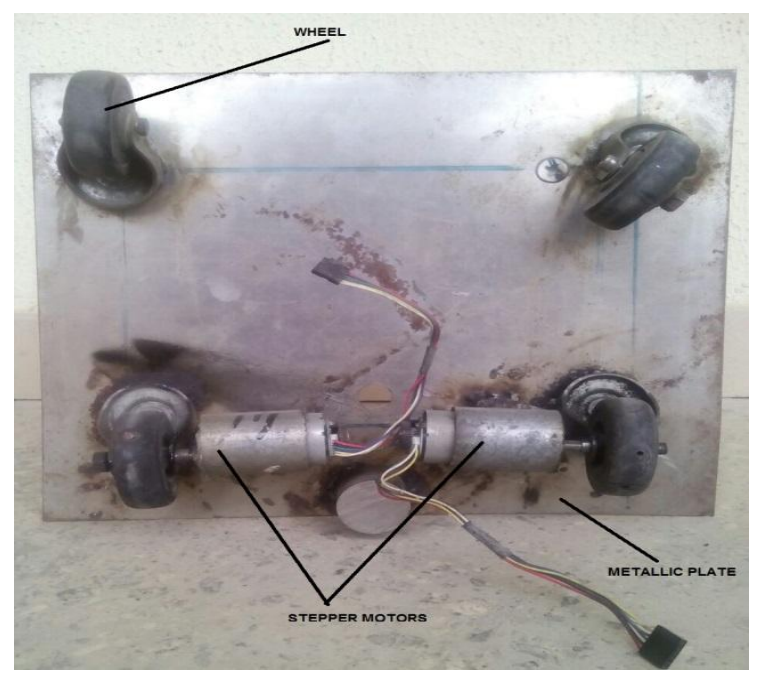

Figure 8. The wheel section of the semi-humanoid robot

In the stage, the stepper motor mechanism is illustrated. This stepper motor is systematically placed in the neck area to move the head in the right and left direction when signaled by the controller. The controller in turn accepted signal from the motion sensors when trespassed by an object or a body coming closer to the robot body at about $1 \mathrm{~m}$. The stepper mechanism design is achieved by a gear system attached to the motor shaft and the removable head of the robot. The gears are connected to each other which make the head movable. The head is program by the controller to count twenty (20) count left and right when signaled to move. The program (software) design for this stepper motor was written based on a certain calculation done for it. The stepper motion has each step of the revolution at $1.8^{\circ}$ and to achieve 20 counts to the right or left; $360^{\circ}$ is divided by $1.8^{\circ}$ to obtain 200 counts in one (1) revolution. Since, the robot need to move at $180^{\circ}$ axis (right or left), further calculation was done by dividing 200 by 2 resulting in 100 counts for $180^{\circ}$ axis range. This 100 count allows 50 counts to either the right or left depending on the direction the robot head moves. In the end, in other not to exceed the given $180^{\circ}$ axis (50 counts in either direction), 20 counts to both direction was used to program the controller for the head movement.

The final stage was the interfacing and interconnection of the components in each section developed in the above stated stages.

\section{RESULTS AND DISCUSSION}

This research endeavor has produced a disruptive innovative device than can comfortably compete with the existing Teleconferencing and Telepresence technologies. Another achievement is the production of a complete physical Telepresence device that has the ability and capability to replicate the exact image and figure of the remote presenter.

Figure 9 below shows the picture of the completed semihumanoid robotic teacher using a plastic mannequin.

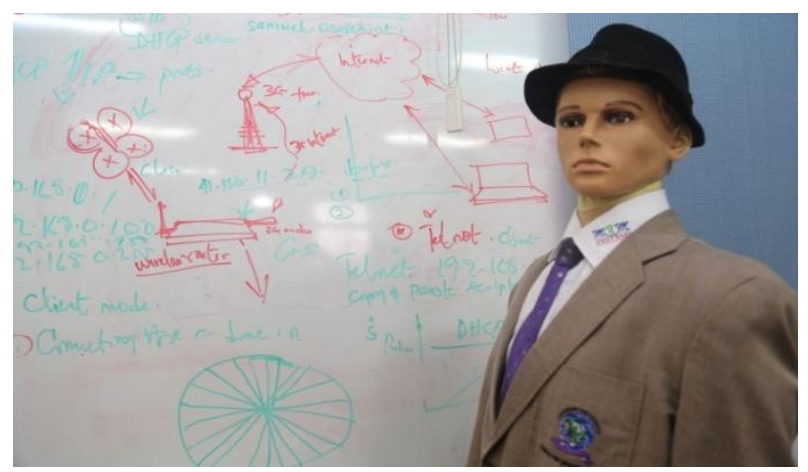

Figure 9. A complete semi - humanoid system for DLI

To further highlight the advantages of the newly developed system, it was compared with other existing systems. The factors taken into consideration include the cost of deployment, the pictorial quality at the student's end, bandwidth requirement at end point, number of participants supported, camera position and its interoperability with other systems. The results obtained are summarily presented in Table 1 below.

\section{CONCLUSION}

The authors have successfully used a simple, cheap, and affordable plastic mannequin as a carcass for the embedded electronics.

A Pan Tilt and Zoom (PTZ) camera is embedded in the eyes of the mannequin that can be remotely controlled by its own software or any free one online; making it possible for us to have a two way audio / video commutations between the class and the remote expert.

All the subsystems of the robotic teacher have been well tested and their respective excellent performances have cumulatively enhanced the system to holistically perform the desired functionality. The developed web application for the movement control also worked perfectly as designed. 
We conclude that we have developed a semi-humanoid remote controlled DLI lecturer that any educationist can log in from anywhere in the world to deliver a lecture in a full physical telepresence format

The implementation and use of this system in our institutions of higher learning will no doubt further boost the quality of education and give the third world countries assess to one of the most advanced technologies in distance learning.

\section{ACKNOWLEDGEMENT}

The authors acknowledge Mr.Akindele Ayoola of the Department of Electrical and Information Engineering, Covenant University, Ota, Nigeria for his support in the implementation of the project.

Table 1: Comparison of Developed System

\begin{tabular}{|c|c|c|c|c|}
\hline Capability & $\begin{array}{c}\text { Video } \\
\text { Confere } \\
\text { ncing }\end{array}$ & $\begin{array}{c}\text { HD Video } \\
\text { Conferen } \\
\text { cing \& } \\
\text { Personal } \\
\text { Teleprese } \\
\text { nce }\end{array}$ & $\begin{array}{c}\text { Telepre } \\
\text { sence }\end{array}$ & $\begin{array}{c}\text { Semi- } \\
\text { Humanoid } \\
\text { Mannequin }\end{array}$ \\
\hline Cost & $\begin{array}{l}\text { Free to } \\
\$ 100 \mathrm{~s}\end{array}$ & $>\$ 1000 \mathrm{~s}$ & $\begin{array}{c}\$ 10 \mathrm{k} \text { to } \\
100 \mathrm{k}\end{array}$ & $<\$ 1000$ s \\
\hline $\begin{array}{l}\text { Picture } \\
\text { Quality }\end{array}$ & $\begin{array}{l}\text { Poor- } \\
\text { Good }\end{array}$ & $\begin{array}{c}\text { Good - } \\
\text { Excellent }\end{array}$ & $\begin{array}{c}\text { Excellen } \\
\mathrm{t}\end{array}$ & Excellent \\
\hline $\begin{array}{c}\text { Bandwidth } \\
\text { Requiremen } \\
\text { t at End } \\
\text { Point }\end{array}$ & $\begin{array}{c}100 \text { of } \\
\text { Kbps }\end{array}$ & $\begin{array}{c}\text { 100kbps - } \\
\text { Mbps }\end{array}$ & $\begin{array}{c}1 \mathrm{Mbps} \\
- \\
5 \mathrm{Mbps}\end{array}$ & $\begin{array}{l}\text { 100kbps to } \\
\text { Mbps }\end{array}$ \\
\hline $\begin{array}{c}\text { No. of } \\
\text { Participants } \\
\text { Supported } \\
\end{array}$ & $\begin{array}{l}\text { Usually } \\
\text { Two (2) }\end{array}$ & Two & Many & Very Many \\
\hline $\begin{array}{l}\text { Interoperabi } \\
\text { lity with } \\
\text { other } \\
\text { systems } \\
\end{array}$ & $\begin{array}{c}\text { Commo } \\
\mathrm{n}\end{array}$ & Limited & $\begin{array}{c}\text { Very } \\
\text { Limited }\end{array}$ & Common \\
\hline $\begin{array}{l}\text { Camera } \\
\text { Position }\end{array}$ & $\begin{array}{l}\text { Fixed or } \\
\text { Variable }\end{array}$ & Variable & $\begin{array}{l}\text { Fixed, } \\
\text { requires } \\
\text { room } \\
\text { preparat } \\
\text { ion } \\
\end{array}$ & $\begin{array}{c}\text { Variable } \\
\text { (Pan, Tilt } \\
\text { and Zoom } \\
\text { Camera) }\end{array}$ \\
\hline
\end{tabular}

\section{REFERENCES}

[1] 2013/2014 Education For All (EFA) Global Monitoring Report, "Teaching and Learning: Achieving Quality for all"(C) United Nations Educational, Scientific and Cultural Organization (UNESCO) 2014

[2] TelePresence in Education, A Cisco White Paper (C) 2007, Cisco Systems Incorporated (Available Online: www.cisco.com/web/strategy/education/telepresence_ for_schools.html)

[3] Teachers and Educational Quality: Monitoring Global Needs for 2015; ( ) UNESCO Institute for Statistics (UIS) 2006 (Available Online: www.uis.unesco.org/publications/teachers2006

[4] Internet of Learning-Things," Edutech Associates, August 2013, http://bit.ly/1g3wPGP
[5] Facing the World: Telepresence in Education, A publication of California State University, Monterey Bay; Sponsored by Cisco Systems

[6] "NMC Horizon Report, 2013: HiEd Edition," The New Media Consortium http://www.nmc.org/publications/2013-horizon-reporthigher-ed

[7] http://supermechanical.com/twine/

[8] "Embracing the Internet of Everything To Capture Your Share of \$14.4 Trillion," Cisco, 2013.

[9] Allison C.R, Allison C.N, "The goals of E-Learning and Distance Learning towards the educational development of Nigerian Public Service", International Journal of Research

[10] r Trends and Technology (IJCTT), Vol.12, No 2, June 2014 ISSN: $2231 \quad-5381$ (Available Online: http://www.ijettjournal.org)

[11] P.C. et al., "What drives a successful e-Learning? An empirical investigation of the critical factors influencing learner satisfaction", Computers \& Education (2007), doi:10.1016/j.compedu.2006.11.007 (Available online at www.sciencedirect.com)

[12] Hassan Selim, "E-Learning Critical Success Factors: An Exploratory Investigation of Students Perceptions", Managing Modern Organizations Through Information Technology, Proceedings of the 2005 Information Resources Management Association International Conference, Copyright () 2005, Idea Group Inc

[13] Zaman M.T, Ahmed M.S, "Design and Construction of a Multipurpose Robot", International Journal of Automation, Control and Intelligent Systems, published by American Institute of Science, Vol.1, No. 2, 2015, pp34-46 (Available Online: http://www.aisience.org/journal/ijacis)

[14] Wesley L. Stone, The History of Robotics , In book Robotics and Automation Handbook, Thomas R. Kurfess; Publisher: CRC Press LLC, USA, 2005; pp. 1320.

[15] Aboshosha, A. Zell, "Adaptation of Rescue Robot Behavior in Unknown Terrains Based on Stochastic and Fuzzy Logic Approaches", In: Proceeding of IEEE/RSJ International Conference on Intelligent Robots and Systems-2003(IROS2003), Vol. 3, 27-31 Oct, 2003, pp.2859-2864.

[16] M Veloso, P Stone, and M Bowling, "Anticipation as a Key for Collaboration in a Team of Agents: A Case Study in Robotic Soccer", In: Proceedings of SPIE Sensor Fusion and Decentralized Control in Robotic Systems II, SPIE, Bellingham, WA, September 1999, pp. 134-143.

[17] Q Liu, Y Lu and C Xie, "Optimal Genetic Fuzzy Obstacle Avoidance Controller of Autonomous Mobile Robot Based On Ultrasonic Sensors", In: Proceeding of IEEE International Conference on Robotics and Biometrics, Kunming, China, 17-20 Dec, 2006, pp. 125129. 